\title{
A 100 Gbps True Full-Duplex Link with Interference Cancellation in the Background
}

\author{
Sandeep Goyal and Shalabh Gupta
}

\begin{abstract}
In this paper, we introduce the concept of true full-duplexing (TFD) for high-speed interconnects. Full-duplex transceivers at the two ends of an interconnect can support simultaneous bidirectional data transfer. Full-duplexing can help in increasing the throughput per lane and also enable higher data transfer bandwidths without an increase in the routing density. The proposed TFD approach allows for the use of independent modulation schemes as well as independent baudrates by the transceivers on either side of the interconnect. The approach also obviates the requirement of a dedicated startup protocol or a training sequence for cancellation of nearend interference in the TFD transceivers. In this work, we have used a correlation-based cancellation technique which can support background cancellation of the interference. Here, we demonstrate a 100 Gbps TFD link over a $1 \mathrm{~m}$ long coaxial cable with off-the-shelf components, which is the first demonstration of a full-duplex communication link at such a high data rate.
\end{abstract}

Index Terms-Adaptive echo cancellation, correlation, fullduplex, high-speed serial links, self-interference, simultaneous bidirectional, true full-duplex (TFD).

\section{INTRODUCTION}

High-performance computation engines are required for artificial intelligence, big data, and deep-learning architectures. These architectures use high-speed data interconnects to interface many high-performance modules like multi-core processors, high-bandwidth memories, graphics processors, network interfacing cards, and machine learning accelerators [1]. The performance of digital circuitry in these modules continuously improves with device scaling. The modules can process a large amount of data at a rapid pace and require very fast data exchanges. A significant effort is being made to further enhance the performance of the engines consisting of multiple such modules using heterogeneous integration (HI) [2]. With HI, modules with highly optimized individual performances, termed as chiplets, are integrated either over a high-density package or on a common substrate to achieve data exchange throughputs as high as (0.1-1) Tbps/mm (die-edge) [3], [4]. To match this increase in the data exchange rate among the system modules, interconnects with better throughputs and lower latencies are required.

To meet such throughputs, multi-Gbps simplex and duplex interconnect standards are being developed. Among the simplex solutions, AIB-Plus, BoW, BoW-T, PCIe 6.0, and Kandou bus are recent short reach standards [5]-[8], whereas, USB 3.2, SATA 3.5, and Thunderbolt 3 are the long-reach standards [9][11]. These simplex solutions use either a large number of slow

The authors are with the Department of Electrical Engineering, Indian Institute of Technology Bombay, Mumbai - 400076, India (email: sandeepgoyal@ee.iitb.ac.in; shalabh@ee.iitb.ac.in). lanes [5], [7], a small number of high-speed lanes [6], [9][11], re-configurable transceivers [12]-[14], chord signalling (bit-wire encoding) [8], or multi-level signalling schemes [15]. In the simplex standards, except for the Kandou bus where a chord signalling scheme is used, crosstalk is a critical issue affecting signal integrity. The crosstalk or coupling from the nearby aggressors becomes even more severe with an increase in the routing density or operating baud rate [16]-[22]. The reduction of the crosstalk in the simplex standards demands either an increased lane spacing or a decreased operating baud rate, thus lowering the throughput/die-edge.

An alternative solution to reduce the crosstalk without affecting the throughput is to support simultaneous bidirectional (SBD) transfer of data on the same interconnect. Full-duplex (FD) or SBD standards support simultaneous data transmission and reception with a transceiver on either side of the electrical interconnect. These bidirectional standards, such as Ethernet [23] and BoW-BiDi [7] utilize a channel's bilateral nature to reduce the lane density by $50 \%$, and thus lowering the effect of the crosstalk. The SBD transceivers suffer from the presence of interference from their own transmitters. The transceivers receive a composite signal $\mathrm{S}_{\mathrm{TR}}(\mathrm{t})$ at the input-output (IO) port. $\mathrm{S}_{\mathrm{TR}}(\mathrm{t})$ contains (i) a far-end (FE) signal $\mathrm{S}_{\mathrm{F}}$ and (ii) an interference signal $S_{N I}$ - due to the near-end (NE) transceiver. The $\mathrm{S}_{\mathrm{NI}}$ includes a strong self-interference (SI) and echoes due to reflections from locations in the link with impedance discontinuities. The presence of $\mathrm{S}_{\mathrm{NI}}$ significantly affects the bit-error-ratio (BER) at the transceiver, and therefore, it must be suppressed to faithfully extract the FE information from $\mathrm{S}_{\mathrm{TR}}(\mathrm{t})$ without much penalty on the link performance.

Most interference cancellation approaches [7], [23]-[38] use hybrids for suppressing the SI, and digital domain cancellers for minimizing the echoes and any remnants of the SI (post suppression). The use of the hybrid relaxes the dynamic range requirements of the analog-to-digital-converter (ADC) used by the transceiver. The ADC performs the required digitization, to further minimize the interference digitally. The digital interference cancellers use adaptation engines based on the leastmean-square (LMS) or sign-sign LMS (SSLMS) algorithms. The engines are used for suppressing the time-dependent variations in the amplitude, baud-rate, and pulse shape of the NE transmitted signal. The digital cancellers need synchronization or clock forwarding between the two transceivers in a masterslave configuration [35]. The dependence of these cancellation approaches on the FE transceiver makes calibrating the hybrid and training the canceller challenging, especially when the FE transmitter is active. This limits the utility of these approaches to systems that allow frequent training. 


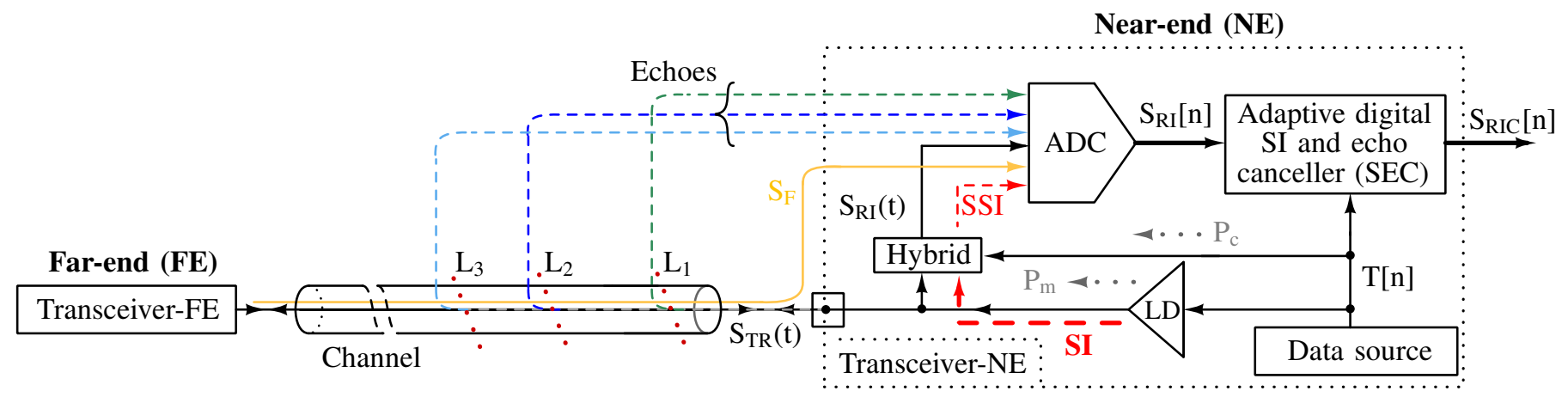

Fig. 1: A general approach for interference cancellation in high-speed SBD links to extract the information transmitted by the far-end (FE) transceiver. Here, $L_{i}-i^{\text {th }}$ reflecting location of the link; $P_{m}$ - the main signal path; $P_{c}-$ the interference cancellation path; LD - line driver. Various components of the NE interference i.e. the SI, SSI, and echoes are shown using dashed lines.

TABLE I: List of signal abbreviations used

\begin{tabular}{|l|l|l|l|}
\hline $\mathrm{S}_{\mathrm{TR}}$ & Composite signal & rSI & Residual SI \\
\hline $\mathrm{S}_{\mathrm{F}}$ & Far-end signal & $\mathrm{S}_{\mathrm{NI}}$ & Near-end interference \\
\hline $\mathrm{T}[\mathrm{n}]$ & Near-end digital data & $\mathrm{S}_{\mathrm{C}}$ & Interference cancellation tap \\
\hline $\mathrm{S}_{\mathrm{TA}}$ & SI-suppression tap & $\mathrm{S}_{\mathrm{T}}$ & Near-end transmitted signal \\
\hline $\mathrm{F}[\mathrm{n}]$ & Far-end digital data & $\mathrm{S}_{\mathrm{RIC}}$ & $\begin{array}{l}\text { Received far-end signal post } \\
\text { interference cancellation }\end{array}$ \\
\hline $\mathrm{S}_{\mathrm{FR}}$ & $\begin{array}{l}\text { Recovered and equalized } \\
\text { far-end signal }\end{array}$ & $\mathrm{S}_{\mathrm{RI}}$ & $\begin{array}{l}\text { Received far-end signal with } \\
\text { interference }\end{array}$ \\
\hline
\end{tabular}

To overcome the limitations in full-duplexing mentioned above, we propose the concept of true full-duplexing (TFD) for SBD links. In TFD links, cancellation for $\mathrm{S}_{\mathrm{NI}}$ is independent of the baud rate and the signalling scheme used in $\mathrm{S}_{\mathrm{F}}$. The TFD link uses a correlation-based interference cancellation technique that allows for background cancellation of the SI and echoes present in $S_{T R}(t)$, even in the presence of $S_{F}$ [39], [40]. The interference canceller, thus doesn't need a training sequence and can be trained with an active FE transmitter. Using this technique, we demonstrate a TFD link with an aggregate data rate of $100 \mathrm{Gbps}$ over a $1 \mathrm{~m}$ long co-axial cable. To the best of our knowledge, the demonstrated link has the highest bidirectional throughput achieved over a single-lane.

The rest of the paper is organized as follows. The list of signal abbreviations used is provided in Table I. We review various SI and echo cancellation techniques and their limitations in Section II. Section III presents our correlationbased interference cancellation approach used in the TFD link. Section IV describes the measurement setup and the results obtained from a $100 \mathrm{Gbps}$ TFD link. Section V concludes this work.

\section{SI AND ECHO CANCELLATION IN CONVENTIONAL SBD LINKS}

In SBD links as shown in Fig. $1, \mathrm{~S}_{\mathrm{TR}}(\mathrm{t})$ at the $\mathrm{IO}$ port of Transceiver-NE comprises of a strong SI and echoes due to the $\mathrm{NE}$ transmitter, and a weak but desired $\mathrm{S}_{\mathrm{F}}$ from TransceiverFE. Even though the SI and echoes are a form of the NE transmitted signal but have different origins, strengths, timespans, and delays. These differences in the two interferers require different approaches for their cancellation.

The echoes are reflections of $S_{T}(t)$ from the channel and transceiver/package interfaces. The strength and instant of the echo occurrence depend on the operating baud-rate, channel characteristic, channel length, reflection coefficient of the interface, and round-trip delay from the reflecting interface. With these dependencies, the echoes get dispersed in time and magnitude. This dispersive nature of the echoes makes an all analog echo cancellation approach power inefficient. The approach requires many high-speed amplifiers and delay elements, which consumes a lot of power [41]. Therefore, the echoes are cancelled using an adaptive digital echo cancellation approach along with an ADC and a set of digitally delayed transmitted taps. On the other hand, the SI is a strong and slightly delayed form of $S_{T}(t)$, and can be suppressed efficiently in the analog domain by using a hybrid and few delay elements.

Conventionally, to suppress the SI, the SBD links with low operating baud-rates use hybrids with passive components such as T-coils or magnetic bridges [42]-[44]. In contrast, hybrids for high baud-rate links use active components [7], [23]-[35]. These hybrids need tuning or calibration to matched delays and frequency responses of the main signal path $\mathrm{P}_{\mathrm{m}}$ and the interference cancellation path $\mathrm{P}_{\mathrm{c}}$, as shown in Fig. 1 . Mismatches in the spectral responses or delays in the two paths may arise due to variations in the interfacing conditions, load impedance, process, voltage, and temperature. These mismatches result in partial cancellation of the SI, leaving a "suppressed-SI" (SSI) in $\mathrm{S}_{\mathrm{RI}}(\mathrm{t})$ at the input of the transceiver ADC. In the SBD links, the hybrids enable the use of a low dynamic range $\mathrm{ADC}$ by the transceiver. Henceforth, a power efficient interference cancellation approach is to:

(i) Suppress the SI present in $\mathrm{S}_{\mathrm{TR}}(\mathrm{t})$ to $\mathrm{SSI}$ in the analog domain - using a hybrid and a replica of the transmitted data $T[n]$.

(ii) Digitize the SSI and echoes along with $\mathrm{S}_{\mathrm{F}}$ present in the received signal $S_{R I}(t)$, using a low dynamic range ADC - to reduce power consumption of the SBD transceiver.

(iii) Minimize the NE interference present in the $\mathrm{S}_{\mathrm{RI}}[\mathrm{n}]$ using an adaptive digital SI and echo canceller (SEC) to obtain $\mathrm{S}_{\mathrm{RIC}}[\mathrm{n}]$.

To recover the FE information, most digital cancellers used for minimizing the SSI and echoes, apart from initialization also need synchronization between Transceiver-NE and Transceiver-FE [7], [23]-[35]. Here, we propose the use of TFD in high-speed links as well as in high-density interconnects, where these requirements for minimization are obviated by the use of a correlation-based SEC. 


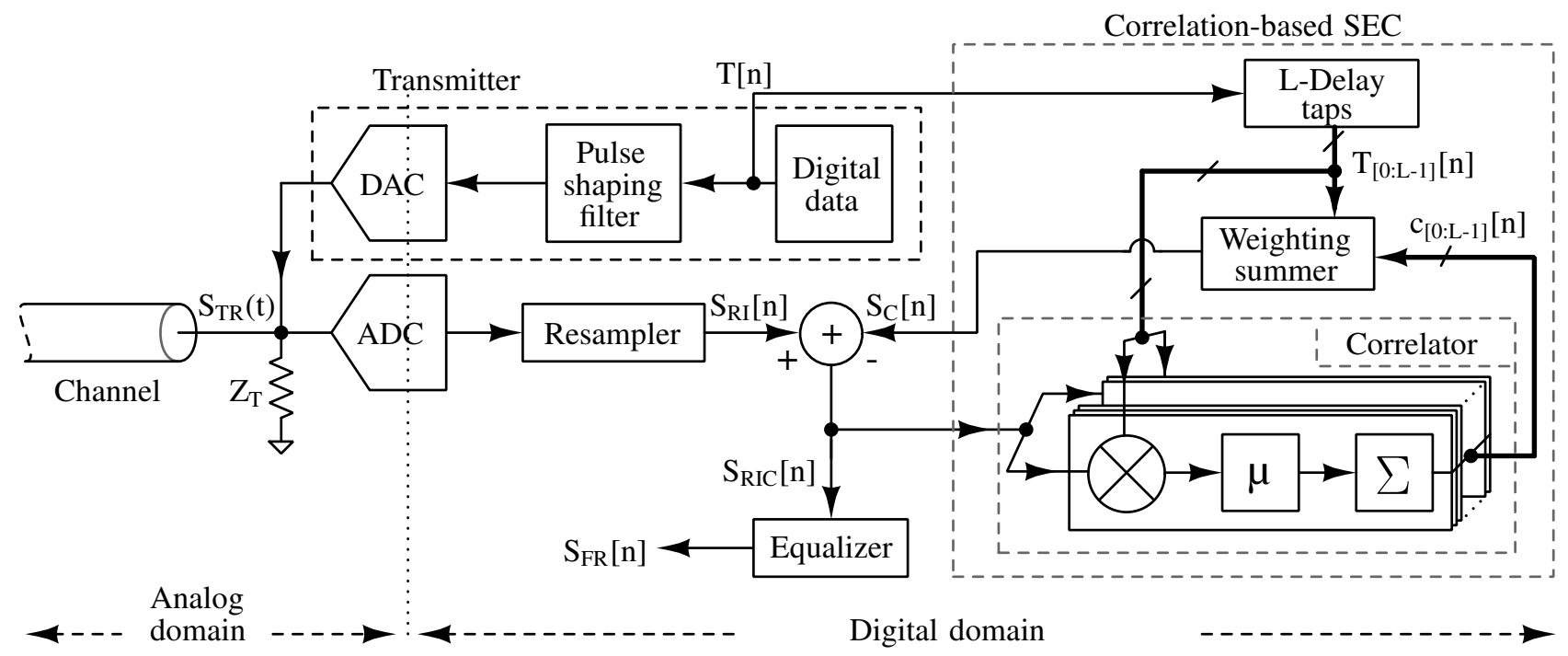

Fig. 2: Block diagram of the proposed TFD transceiver. Here, $\mathrm{Z}_{\mathrm{T}}$ - termination impedance; $\mathrm{c}_{\mathrm{k}}-\mathrm{k}^{\text {th }}$ coefficient of the cancellation filter; $\mathrm{T}[\mathrm{n}]$ - data input; $\mathrm{T}_{\mathrm{k}}[\mathrm{n}]$ - $\mathrm{k}^{\text {th }}$ delayed copy of $\mathrm{T}[\mathrm{n}] ; \Sigma$ - accumulator; $\mu$ - loop update rate; and L - length of the cancellation filter used by the correlation-based SEC.

\section{CORRELATION-BASED INTERFERENCE CANCELLATION IN THE PROPOSED TFD LINKS}

The architecture of the TFD transceiver used on each side of the proposed TFD link is shown in Fig. 2. The transceiver comprises: (i) a transmitter, which has a data source, a pulse shaping filter, and a digital-to-analog-converter (DAC) for signal transmission; (ii) an ADC as the receiver front-end for signal reception and digitization; and (iii) a correlationbased SEC for the interference cancellation. The transceiver, first digitizes $S_{T R}(t)^{1}$ using an ADC and then re-samples it to obtain $S_{R I}[n]$. The digitized signal $S_{R I}[n]$ contains the $F E$ information as well as the $\mathrm{NE}$ interference. From $\mathrm{S}_{\mathrm{RI}}[\mathrm{n}]$, $\mathrm{S}_{\mathrm{FR}}[\mathrm{n}]$ is then recovered post interference cancellation and equalization, using the correlation-based SEC and an equalizer, respectively.

\section{A. Correlation-based SI and echo canceller}

Major challenge in the TFD operation is to suppress the interferers present in $\mathrm{S}_{\mathrm{TR}}(\mathrm{t})$ without losing the simultaneously received FE information. The proposed TFD link suppresses $\mathrm{S}_{\mathrm{NI}}$ by using a correlation-based cancellation approach to separate-out the FE data from $S_{T R}(t)$. The cancellation approach makes use of an adaptive Wiener filter [45] and the following two facts: (1) the inherent correlation that exists in between $S_{T}$ and $S_{N I}$ (the SI and echoes being delayed versions of $S_{\mathrm{T}}$ ), for minimizing the latter; (2) the practically uncorrelated nature of the information generated by the two independent transceivers, for separating-out $\mathrm{S}_{\mathrm{F}}$. The filter determines the correlation coefficient $c_{k}$ as given by Eq. (1), which represents the degree of correlation present in between $\mathrm{S}_{\mathrm{RI}}[\mathrm{n}]$ and $\mathrm{T}_{\mathrm{k}}[\mathrm{n}]$, and is used for minimizing this correlation. For uncorrelated NE and FE signals, this correlation-based interference cancellation approach is very helpful and unique. Using this approach, the interference cancellers can adjust

\footnotetext{
${ }^{1}$ Here, as an ADC is used directly as the receiver front-end without a hybrid, $\mathrm{S}_{\mathrm{TR}}(\mathrm{t})$ and $\mathrm{S}_{\mathrm{RI}}(\mathrm{t})$ are equivalent.
}

their coefficients even in the presence of $\mathrm{S}_{\mathrm{F}}$. The correlationbased approach, thus enables background cancellation for the interference in the TFD link.

$$
\begin{aligned}
c_{k}[n]= & c_{k}[n-1]+\frac{1}{N} \sum_{k=0}^{N-1}\left\{S_{R I C}[n] \times T_{k}[n]\right\} \\
= & c_{k}[n-1]+\frac{1}{N} \sum_{k=0}^{N-1}\left(S_{F}[n] \times T_{k}[n]\right) \\
& +\frac{1}{N} \sum_{k=0}^{N-1}\left(S_{N I}[n] \times T_{k}[n]\right) \\
& -\frac{1}{N} \sum_{k=0}^{N-1}\left(S_{C}[n] \times T_{k}[n]\right), \\
= & c_{k}[n-1]+r_{\left\{S_{F}, T_{k}\right\}}+r_{\left\{S_{N I}, T_{k}\right\}}-r_{\left\{S_{C}, T_{k}\right\}}, \\
= & c_{k}[n-1]+\Delta c_{k}[n],
\end{aligned}
$$

where, $\mathrm{N}$ - is length of the correlator, $\mathrm{r}_{\{\mathrm{X}, \mathrm{Y}\}}$ - denotes the correlation between $\mathrm{X}$ and $\mathrm{Y}$, and $\mathrm{k}$ - is the filter tap index. For interference cancellation, $\mathrm{r}_{\left\{\mathrm{S}_{\mathrm{NI}}, \mathrm{T}_{\mathrm{k}}\right\}}$ should be equal to $\mathrm{r}_{\left\{\mathrm{S}_{\mathrm{C}}, \mathrm{T}_{\mathrm{k}}\right\}}$, and $\mathrm{r}_{\left\{\mathrm{S}_{\mathrm{F}}, \mathrm{T}_{\mathrm{k}}\right\}}$ should be low. The proposed correlation-based SEC generates a replica interference cancellation tap $S_{C}[n]$ as given by Eq. (2) to cancel $S_{\mathrm{NI}}$ present in $\mathrm{S}_{\mathrm{RI}}[\mathrm{n}]$.

$$
\begin{aligned}
& \mathrm{S}_{\mathrm{C}}[\mathrm{n}]=\sum_{\mathrm{k}=0}^{\mathrm{L}-1}\left\{\mathrm{c}_{\mathrm{k}}[\mathrm{n}] \times \mathrm{T}_{\mathrm{k}}[\mathrm{n}]\right\}, \\
& \mathrm{S}_{\mathrm{RIC}}[\mathrm{n}]=\mathrm{S}_{\mathrm{RI}}[\mathrm{n}]-\mathrm{S}_{\mathrm{C}}[\mathrm{n}] \text {, } \\
& =\mathrm{S}_{\mathrm{F}}[\mathrm{n}]+\mathrm{rSI}[\mathrm{n}] \text {, }
\end{aligned}
$$

where, L - is length of the cancellation filter and $\mathrm{k}$ - is the filter tap index. For the cancellation, the SEC adaptively minimizes $\mathrm{r}_{\left\{\mathrm{S}_{\mathrm{RIC}}, \mathrm{T}_{\mathrm{k}}[\mathrm{n}]\right\}}$, and hence determines the correlation coefficient(s) $c_{k}$ (s) using Eq. (1), (2), and (3). As the SEC tries to minimize only $\mathrm{r}_{\left\{\mathrm{RIC}, \mathrm{T}_{\mathrm{k}}[\mathrm{n}]\right\}}$ and not $\mathrm{S}_{\mathrm{RIC}}$, it preserves the uncorrelated components of $\mathrm{S}_{\mathrm{RIC}}$ from cancellation. This cancellation, thus eliminates the interference and helps in re- 
TABLE II: Cancellation modes supported by the correlationbased SEC

\begin{tabular}{|l|c|c|c|c|}
\hline $\begin{array}{c}\text { Cancellation } \\
\text { mode }\end{array}$ & $\begin{array}{c}\text { NE } \\
\text { transmitter }\end{array}$ & $\begin{array}{c}\text { FE } \\
\text { transmitter }\end{array}$ & $\begin{array}{c}\text { Correlation- } \\
\text { based SEC }\end{array}$ & $\begin{array}{c}\text { SEC } \\
\text { training type }\end{array}$ \\
\hline DPT & On & Off & On & Pre-trained \\
\hline $\begin{array}{l}\text { DBG } \\
\text { (Proposed) }\end{array}$ & On & Don't care & On & Background \\
\hline
\end{tabular}

Here, DPT - digital pre-trained cancellation; and DBG - digital background cancellation.
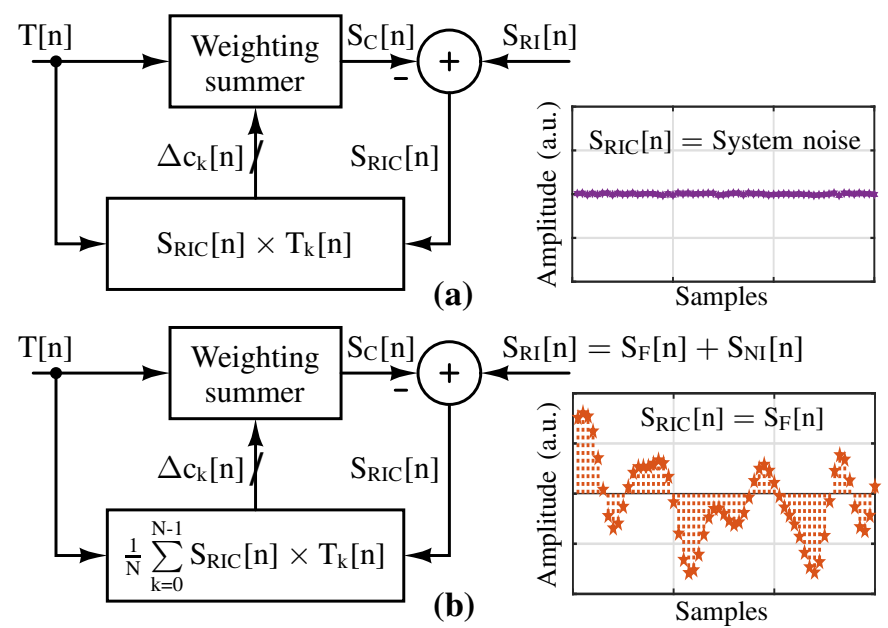

Fig. 3: System model for the SEC along with $S_{\text {RIC }}[n]$ for the supported cancellation mode (a) DPT and (b) DBG.

covering $\mathrm{S}_{\mathrm{FR}}[\mathrm{n}]$ from $\mathrm{S}_{\mathrm{RIC}}[\mathrm{n}]$, wherein, some residual-SI (rSI) might also be present in case of an incomplete interference cancellation.

The proposed SEC supports interference cancellation in the following two modes as listed in Table II.

(i) Digital pre-trained cancellation (DPT): In this mode, to determine the required values of all $c_{k}(s)$ the FE transmitter is deactivated; hence, $\mathrm{S}_{\mathrm{RI}}[\mathrm{n}]$ contains only $\mathrm{S}_{\mathrm{NI}}[\mathrm{n}]$. To cancel $\mathrm{S}_{\mathrm{NI}}[\mathrm{n}]$, the SEC tries to generate a $\mathrm{S}_{\mathrm{C}}[\mathrm{n}]$ that mimics $\mathrm{S}_{\mathrm{RI}}[\mathrm{n}]$ by minimizing $\mathrm{S}_{\mathrm{RIC}}[\mathrm{n}]$ down to system's noise floor, as shown in Fig. 3 (a). Updates in the value of any $c_{k}$ depends only on the correlation between $\mathrm{S}_{\mathrm{RIC}}[\mathrm{n}]$ and $\mathrm{T}_{\mathrm{k}}[\mathrm{n}]$ as given by Eq. (4). For a stationary system, the correlation remains constant and independent of $\mathrm{N}$. In such a scenario, the equivalent correlation can also be determined using the conventional LMS algorithm [46] as given by Eq. (5). In this mode, the SEC needs training at a rate similar to which the characteristics of the channel varies.

$$
\begin{aligned}
\Delta c_{k}[n] & =\frac{1}{N} \sum_{k=0}^{N-1} S_{R I C}[n] \times T_{k}[n], \\
& =r_{\left\{S_{R I C}, T_{k}\right\}} . \\
\Delta c_{k}[n] & =S_{\text {RIC }}[n] \times T_{k}[n] .
\end{aligned}
$$

(ii) Digital background cancellation (DBG): In this mode, the required values of $c_{k}(s)$ are determined in presence

\begin{tabular}{|c|c|c|c|c|}
\hline Test case & Transmitter & $\begin{array}{c}\text { Data } \\
\text { sequence }\end{array}$ & $\begin{array}{l}\text { Signalling } \\
\text { scheme }\end{array}$ & $\begin{array}{c}\text { Cancellation } \\
\text { mode }\end{array}$ \\
\hline \multirow{2}{*}{ Case1t } & $\mathrm{NE}$ & PRBS-11 & PAM4 & \multirow{2}{*}{ DPT } \\
\hline & $\mathrm{FE}$ & Off & $\mathrm{NA}$ & \\
\hline \multirow{2}{*}{ Case1a } & $\mathrm{NE}$ & PRBS-11 & PAM4 & \multirow{2}{*}{ Off } \\
\hline & $\overline{F E}$ & PRBS-15 & PAM4 & \\
\hline \multirow{2}{*}{ Case1b } & $\mathrm{NE}$ & PRBS-11 & PAM4 & \multirow{2}{*}{ Off } \\
\hline & $\mathrm{FE}$ & PRBS-32 & PAM4 & \\
\hline \multirow{2}{*}{ Case $2 \mathrm{a}$} & $\mathrm{NE}$ & PRBS-11 & $\overline{\text { PAM4 }}$ & \multirow{2}{*}{ DBG } \\
\hline & $\mathrm{FE}$ & PRBS-15 & PAM4 & \\
\hline \multirow{2}{*}{ Case $2 b$} & $\mathrm{NE}$ & PRBS-11 & PAM4 & \multirow{2}{*}{ DBG } \\
\hline & FE & PRBS-32 & PAM4 & \\
\hline \multirow{2}{*}{ Case3 } & $\mathrm{NE}$ & PRBS-11 & PAM4 & \multirow{2}{*}{ DBG } \\
\hline & $\mathrm{FE}$ & PRBS-15 & NRZ & \\
\hline
\end{tabular}
of the FE transmission, i.e., $S_{R I}[n]$ contains both $S_{N I}[n]$
TABLE III: Test cases for Matlab ${ }^{\circledR}$ simulations

Here, NRZ - non-return-to-zero; PAM4 - pulse amplitude modulation with 4 signalling levels.

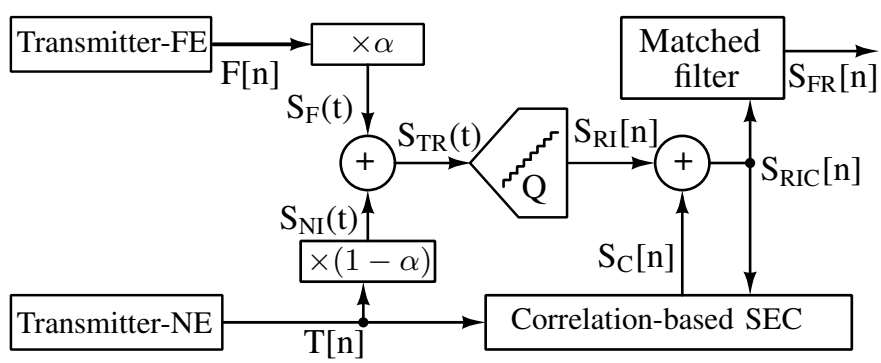

Fig. 4: Simulation setup used for validating the correlationbased interference cancellation approach in $\mathrm{Matlab}^{\circledR}$. Here, $\mathrm{F}[\mathrm{n}]$ - FE transmitted data and Q - Quantizer.

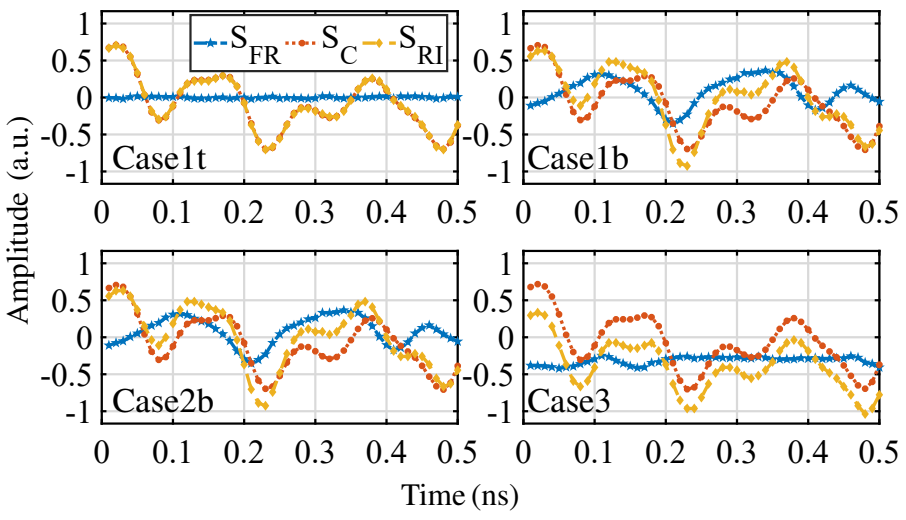

Fig. 5: Various signals of the correlation-based SEC for different test cases as simulated in Matlab ${ }^{\circledR}$.

and $S_{F}[n]$. To cancel $S_{N I}[n]$, the SEC generates a $S_{C}[n]$ by minimizing $\mathrm{r}_{\left\{\mathrm{RIC}, \mathrm{T}_{\mathrm{k}}[\mathrm{n}]\right\}}$. Any update in the value of a $c_{k}$ thus, depends only on the correlation between $S_{\text {RIC }}[n]$ and $T_{k}[n]$ as given by Eq. (4). The minimization, hence reduces $S_{\text {RIC }}[n]$ down to $S_{F}[n]$, as shown in Fig. $3(b)$. This mode supports background training for the SEC, independent of $S_{\mathrm{F}}[n]$ and variations in the channel characteristics.

\section{B. Validation using simulations in Matlab ${ }^{\circledR}$}

Simulations were performed in $\mathrm{Matlab}^{\circledR}$ for validating the used correlation-based interference cancellation approach. The simulation setup is shown in Fig. 4, where Transmitter-NE and 


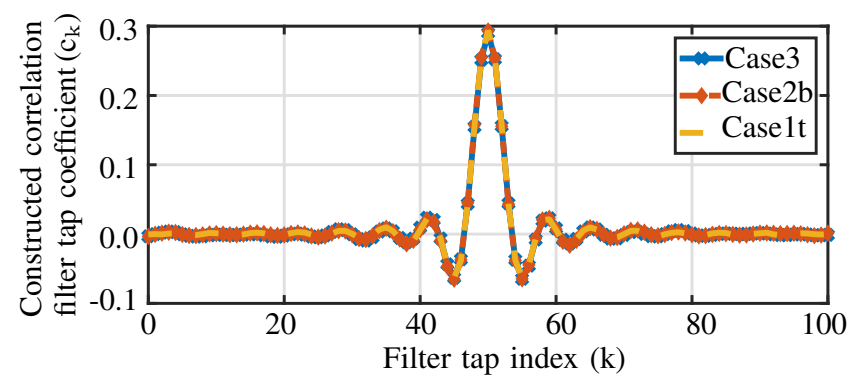

Fig. 6: Coefficients of the correlation filters used for generating the replica interference cancellation tap $\mathrm{S}_{\mathrm{C}}[\mathrm{n}]$ in different test cases simulated in Matlab ${ }^{\circledR}$. The filters constructed for the cancellation using the two SEC modes show a good conformal matching.

Transmitter-FE, respectively generates the NE data $\mathrm{T}[\mathrm{n}]$ and the FE data F[n]. The setup also comprises: (i) a quantizer (Q) used as the receiver front-end; (ii) a matched filter as the receiver; (iii) the correlation-based SEC for suppressing the interference; and (iv) two scalars with gains $\alpha$ and 1- $\alpha$. The scalars are used to vary the fractions of the quantizer dynamic range occupied by $S_{\mathrm{F}}(t)$ and $S_{\mathrm{NI}}(t)$. The functionality of the SEC has been validated, using the test cases as listed in Table III, where, PRBS-XX ${ }^{2}$ is a pseudo-random-bit-sequence of length $2^{X X}-1$ bits.

Fig. 5 shows various signals of the correlation-based SEC in different test cases. The SEC faithfully recovers $S_{\mathrm{FR}}[\mathrm{n}]$ from $\mathrm{S}_{\mathrm{RI}}[\mathrm{n}]$ in both cancellation modes, independent of the modulation scheme used by Transmitter-FE. Correlation filters used for the recovery are shown in Fig. 6. These correlation filters, constructed in the two cancellation modes, show a good conformal matching. The filters were constructed to generate the $\mathrm{S}_{\mathrm{C}}[\mathrm{n}] \mathrm{s}$ used for cancelling the NE interference, i.e. $(1-\alpha) \times \mathrm{T}[\mathrm{n}]$.

For the test cases, case1 and case2, BER is estimated statistically for $S_{\mathrm{FR}}[\mathrm{n}]$, using Eq. (6), as given in [46]. The estimated BERs for the test cases are plotted in Fig. 7. The error performance has been estimated for a system ENOB (effective-number-of-bits) of 5.5 bits.

$$
\mathrm{BER}_{\mathrm{avg}}=\frac{3}{4} \times Q(\sqrt{0.8 \times \text { average SNR per bit }}),
$$

where, SNR is the ratio of the signal power and noise power. The plots show an improvement in the BER as the strength of the interference decreases for all the cases. This improvement in the BER is due to the availability of more resolution bits for the FE signal.

The BER curves for case1a and case $1 b$, where a pretrained filter (constructed in case1t) has been used for the cancellation, show similar error performance irrespective of the used FE data sequence. On the other hand, the BER plot for case $2 \mathrm{~b}$ shows an error performance similar to case $1 \mathrm{a} /$ case $1 \mathrm{~b}$ but better than case2a. The performance improves because case $2 b$ has a lower cross-correlation between the FE and NE data sequences as compared to case $2 \mathrm{a}$. Thus, as the cross-

\footnotetext{
${ }^{2}$ The higher the difference between $\mathrm{XX}$ values of the two PRBS sequences lesser will be the cross-correlation present in between the two.
}

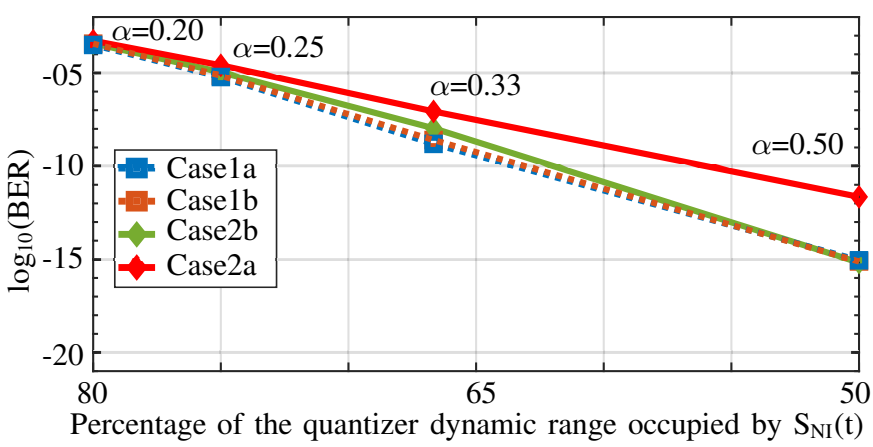

Fig. 7: Estimated BER for the recovered FE signal $S_{\mathrm{FR}}[\mathrm{n}]$. The BER improves with a decrease in the strength of the interference. The plots show an improvement in the BER for the background cancellation mode as the cross-correlation between the FE and the NE data decreases.

TABLE IV: List of the TFD links demonstrated.

\begin{tabular}{|c|c|c|c|c|c|}
\hline \multirow{3}{*}{ TFD link } & \multicolumn{2}{|c|}{ Transmitter-NE } & \multicolumn{2}{|c|}{ Transmitter-FE } & \multirow{3}{*}{$\begin{array}{r}\text { Aggregate } \\
\text { data rate }\end{array}$} \\
\hline & \multicolumn{2}{|c|}{$\mathrm{SQ}_{1}:$ PRBS-11 } & \multicolumn{2}{|c|}{$\mathrm{SQ}_{2}: \mathrm{PRBS}-15$} & \\
\hline & $\begin{array}{l}\text { Baud-rate } \\
\text { (data-rate) }\end{array}$ & $\begin{array}{l}\text { Signalling } \\
\text { scheme }\end{array}$ & $\begin{array}{l}\text { Baud-rate } \\
\text { (data-rate) }\end{array}$ & $\begin{array}{l}\text { Signalling } \\
\text { scheme }\end{array}$ & \\
\hline $\mathrm{LA}_{\mathrm{PAM} 4}$ & $\begin{array}{l}25 \text { Gbaud } \\
\text { (50 Gbps) }\end{array}$ & PAM4 & $\begin{array}{l}25.6 \mathrm{Gbaud} \\
(51.2 \mathrm{Gbps})\end{array}$ & PAM4 & $101.2 \mathrm{Gbps}$ \\
\hline LB & $\begin{array}{l}25 \text { Gbaud } \\
\text { (50 Gbps) }\end{array}$ & PAM4 & $\begin{array}{l}25 \text { Gbaud } \\
(50 \text { Gbps })\end{array}$ & PAM4 & $100 \mathrm{Gbps}$ \\
\hline $\mathrm{LC}_{\mathrm{PAM} 4}$ & $\begin{array}{l}20 \text { Gbaud } \\
(40 \text { Gbps })\end{array}$ & PAM4 & $\begin{array}{l}20 \text { Gbaud } \\
\text { (40 Gbps) }\end{array}$ & PAM4 & $80 \mathrm{Gbps}$ \\
\hline NRZ & $\begin{array}{l}32 \text { Gbaud } \\
\text { (32 Gbps) }\end{array}$ & NRZ & $\begin{array}{l}32 \text { Gbaud } \\
\text { (32 Gbps) }\end{array}$ & NRZ & 64 Gbps \\
\hline
\end{tabular}

TABLE V: System configurations for measurements.

\begin{tabular}{|l|l|l|}
\hline System configuration & $\mathrm{Ch}_{1}$ (Transmitter-NE) & $\mathrm{Ch}_{1}$ (Transmitter-FE) \\
\hline
\end{tabular}

\begin{tabular}{|l|c|c|}
\hline SC1 & On & On \\
\hline SC2 & Off & On \\
\hline
\end{tabular}

correlation between the FE and NE data decreases, the two operating modes of the SEC, i.e. DBG and DPT, have similar error performances. Therefore, with uncorrelated $\mathrm{NE}$ and FE signals, the correlation-based SEC can reliably operate in the background - to eliminate $S_{\mathrm{NI}}$ independent of modulationschemes used by the two transceivers. This approach, thus obviates the need to have a dedicated startup protocol for the two transceivers used in the TFD links, without compromising on the link error performance.

\section{MEASUREMENT SETUP AND RESUlTS}

Measurements have been performed for demonstrating the TFD links as given in Table IV, over a $1 \mathrm{~m}$ long PE-P160 coaxial cable. The measurement setup, as shown in Fig. 8, uses a correlation-based SEC for the interference cancellation in the digital domain. The digital domain cancellation was performed on the signals received, with and without the SI-suppression performed at the hardware level. The TFD links have been demonstrated for a channel response as shown in Fig. 9, using bench-top equipment, which include

- A Keysight DSOZ204A Infiniium oscilloscope with measurement bandwidth of $20 \mathrm{GHz}$ - used for receiving $\mathrm{S}_{\mathrm{RI}}(\mathrm{t})$. 


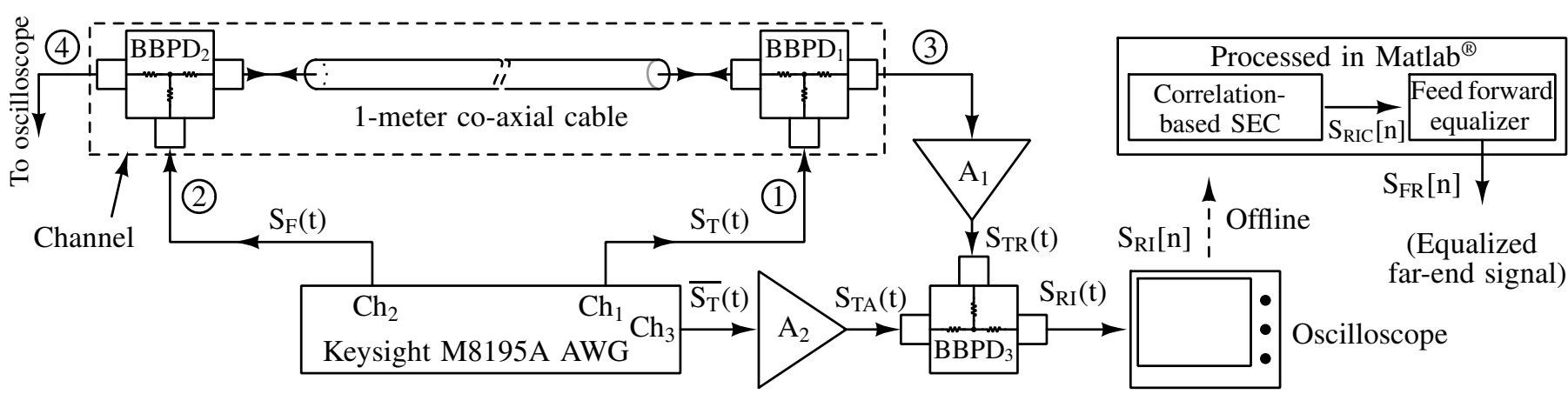

Fig. 8: Measurement setup used for demonstration of the TFD links using off-the-shelf components. The SI has been suppressed in the analog domain using a SI-suppression tap $\mathrm{S}_{\mathrm{TA}}(\mathrm{t})$, and the SSI and echoes are further cancelled in the digital domain using the correlation-based SEC. Here, $S_{\mathrm{FR}}[\mathrm{n}]$ - equalized $\mathrm{S}_{\mathrm{RIC}}[\mathrm{n}] ; \mathrm{S}_{\mathrm{T}}(\mathrm{t})$ - NE transmitted signal; $\mathrm{S}_{\mathrm{F}}(\mathrm{t})$ - FE transmitted signal; $\overline{S_{T}}(t)$ - inverted copy of $S_{T}(t) ; C_{i}-i^{\text {th }}$ channel of the AWG; and $A_{i}-i^{\text {th }}$ used amplifier.

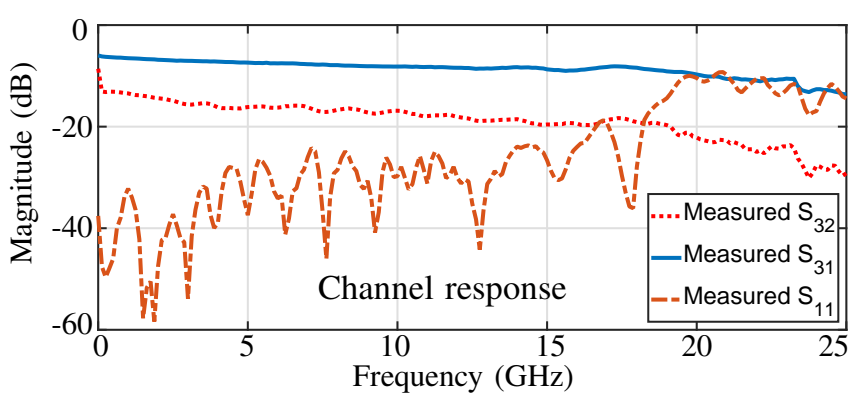

Fig. 9: Response of the channel used for demonstration of the TFD links. Plot shows a relative channel loss, i.e. $\mathrm{S}_{31}-\mathrm{S}_{32}$, of nearly $10 \mathrm{~dB}$ at $12.5 \mathrm{GHz}$.

- A Keysight M8195A 2-slot AXIe arbitrary waveform generator $(\mathrm{AWG})$ for generation of the $\mathrm{NE}$ signal $\mathrm{S}_{\mathrm{T}}(\mathrm{t})$ and the FE signal $S_{\mathrm{F}}(\mathrm{t})$, and a SI-suppression tap $\mathrm{S}_{\mathrm{TA}}(\mathrm{t})$. The $S_{T A}(t)$ is generated using $\overline{S_{T}}(t)$, and has been used for performing the SI-suppression in the analog domain.

The measurement setup, as shown in Fig. 8, consists of three $50 \Omega 3$-port resistive broadband power dividers/combiners (BBPD)s. Each of these BBPDs has a bandwidth of $18 \mathrm{GHz}$ and an insertion loss of at least $6 \mathrm{~dB}$. In this setup, the $\mathrm{BBPD}_{1} / \mathrm{BBPD}_{2}$ combines the desired $\mathrm{FE}$ signal $\mathrm{S}_{\mathrm{F}}(\mathrm{t})$ and the NE interference i.e. the undesired SI and echoes from the $\mathrm{NE}$ transmitter. Whereas, the $\mathrm{BBPD}_{3}$ was used to perform the SI-suppression, by summing the signals $\mathrm{S}_{\mathrm{TR}}(\mathrm{t})$ and $\mathrm{S}_{\mathrm{TA}}(\mathrm{t})$. The setup was operated in the measurement configurations as given in Table $\mathrm{V}$. The number of available resolution bits for the measurements was determined by curve fitting sinusoidal waves of frequency $1 \mathrm{GHz}$ [47]. The system configurations SC1 and SC2, have a lower number of available resolution bits as compared to the standalone oscilloscope, as shown in Fig. 10. The decrease in the number of resolution bits is due to the additional noise received from the DACs of the AWG channels $\left(\mathrm{Ch}_{1}\right.$ and $\left.\mathrm{Ch}_{2}\right)$ and from the amplifiers $\mathrm{A}_{1} / \mathrm{A}_{2}$, which were used as buffers and are shown in Fig. 8.

For the measurements, the $S_{T}(t)$ and $S_{F}(t)$ were transmitted from the two ends of the channel; and the received signal $\mathrm{S}_{\mathrm{RI}}(\mathrm{t})$ was sampled using the oscilloscope at a sample rate of $80 \mathrm{GSps}$. The $\mathrm{S}_{\mathrm{RI}}(\mathrm{t})$ contains the desired FE information and the unwanted interference due to the NE signal $S_{T}(t)$. To
TABLE VI: Cancellation modes used in the TFD links.

\begin{tabular}{|l|c|c|c|}
\hline $\begin{array}{c}\text { Cancellation } \\
\text { mode }\end{array}$ & $\begin{array}{c}\text { System } \\
\text { configuration }\end{array}$ & $\begin{array}{c}\mathrm{S}_{\mathrm{TA}}(\mathrm{t}) \text { - SI-suppression } \\
\text { tap }\end{array}$ & $\begin{array}{c}\text { SEC } \\
\text { training type }\end{array}$ \\
\hline DPT & SC1 & Off & Pre-trained \\
\hline DBG & SC1 & Off & Background \\
\hline ADPT & SC1 & On & Pre-trained \\
\hline ADBG & SC1 & On & Background \\
\hline UD & SC2 & Off & Off \\
\hline
\end{tabular}

Here, DPT - digital pre-trained cancellation; DBG - digital background cancellation; ADPT - analog domain suppression plus digital pre-trained cancellation; ADBG - analog domain suppression plus digital background cancellation; UD - unidirectional.

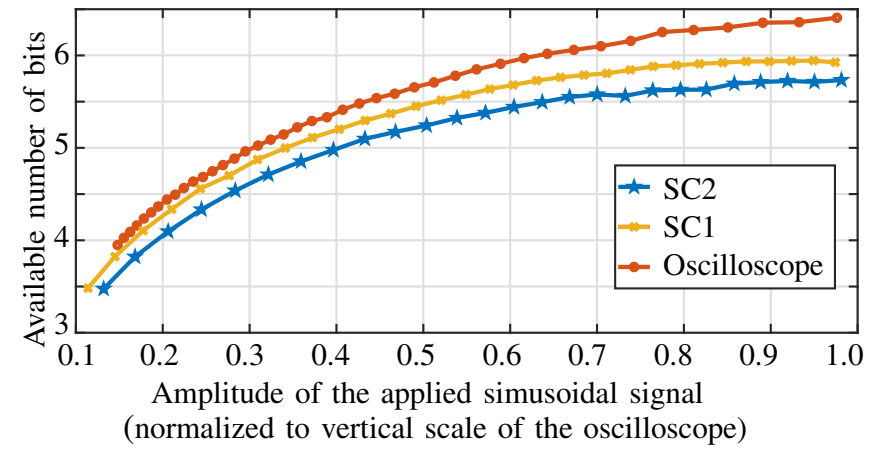

Fig. 10: Measured value of resolution bits available for the standalone oscilloscope, and of the measurement system in configurations: $\mathrm{SC} 1$ and $\mathrm{SC} 2$. The decrease in resolution bits for $\mathrm{SC} 1 / \mathrm{SC} 2$ as compared to the oscilloscope is due the additional noise received from the active AWG channels and the amplifiers.

suppress the interference present in $\mathrm{S}_{\mathrm{RI}}[\mathrm{n}]$, the correlationbased interference cancellation was performed using Matlab ${ }^{\circledR}$, in the modes as mentioned in Table VI. The digital domain cancellation have been performed using pre-trained SECs for the modes DPT and ADPT. While for the modes DBG and ADBG, the SECs operate in the background for the cancellation.

In the cancellation modes DPT/DBG, only the digital domain cancellation has been performed on $\mathrm{S}_{\mathrm{RI}}[\mathrm{n}]$. Whereas, in the cancellation modes ADPT and ADBG, prior to cancellation 


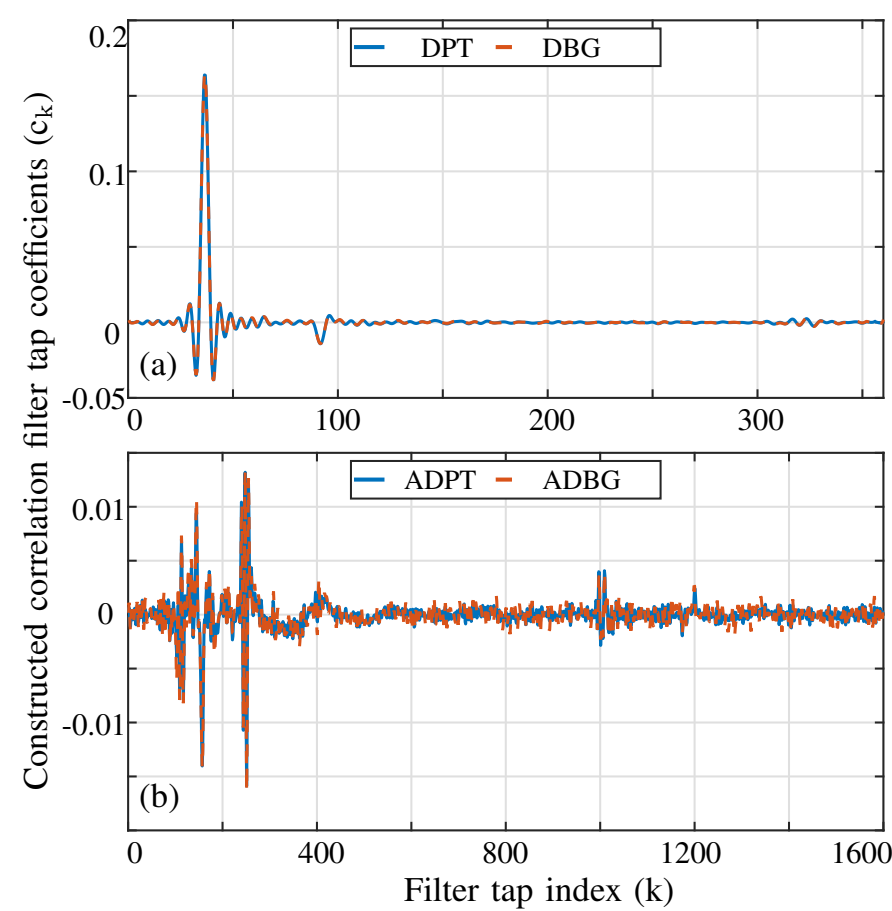

Fig. 11: Coefficients of the digital correlation filters used for cancelling the interference present in $S_{R I}[n]$ : (a) Without the SI-suppression in the analog domain and (b) with the SIsuppression performed using $\mathrm{S}_{\mathrm{TA}}(\mathrm{t})$ at the hardware level.

in the digital domain, the SI-suppression was also performed at the hardware level, by summing $\mathrm{S}_{\mathrm{TR}}(\mathrm{t})$ and $\mathrm{S}_{\mathrm{TA}}(\mathrm{t})$. The use of $\mathrm{S}_{\mathrm{TA}}(\mathrm{t})$ helps in re-claiming the dynamic range of the oscilloscope's ADC, which was else occupied by the SI. Post interference cancellation in these modes, the FE signal was then recovered as $S_{\text {RIC }}[n]$. The $S_{\text {RIC }}[n]$ has been further equalized to obtain $S_{\mathrm{FR}}[\mathrm{n}]$ in $\mathrm{Matlab}^{\circledR}$. The equalization has been performed to compensate for the channel losses using a feedforward equalizer. For the performance evaluation of the SECs used in the TFD links, uni-directional (UD) measurements were also performed. In the UD mode, the SEC is turned-off as $\mathrm{S}_{\mathrm{RI}}[\mathrm{n}]$ contains only the FE signal, and needs only equalization to compensate for the channel losses.

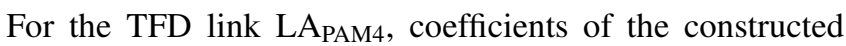
cancellation filters are shown in Fig. 11. To cancel the interference, these filters were used to minimize the correlation present between $S_{R I}[n]$ and the delayed replicas of $S_{T}$. The constructed correlation filters for the mode DPT and DBG plotted in Fig. 11(a) show a strong main lobe along with side lobes. The main lobe is due to a strong SI, whereas the side lobes are because of echoes and the pulse shaping filter used for the data transmission. For the modes, ADPT and ADBG, suppression performed in the analog domain using $\mathrm{S}_{\mathrm{TA}}(\mathrm{t})$ suppresses the main lobe significantly. The filter for the mode ADBG, as shown in Fig. 11(b), because of its larger length, shows a higher variation in the coefficient values as compared to that for the mode ADPT.

Eye-diagrams of the FE signal for the link $\mathrm{LA}_{\mathrm{PAM} 4}$, with and without interference cancellation and equalization, are plotted in Fig. 12. Fig. 12(a) and Fig. 12(b) show eye-diagrams

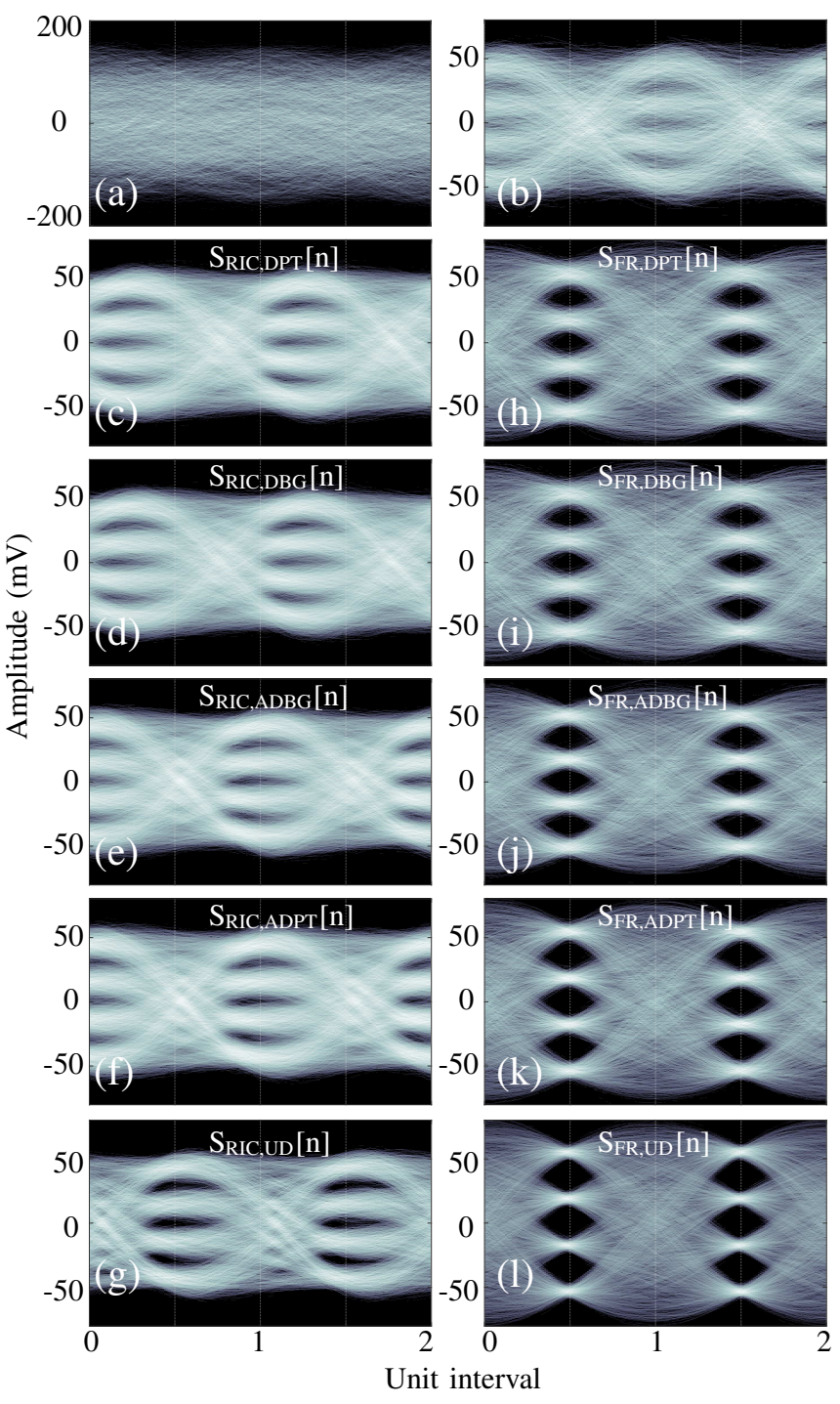

Fig. 12: Eye-diagrams for (a) $S_{R I}[n]$ without any interference cancellation, (b) $\mathrm{S}_{\mathrm{RI}}[\mathrm{n}]$ with SI-suppression performed using the $S_{T A}(t)$ in the analog domain, (c)- $(\mathrm{g})$ recovered $S_{\text {RIC }}[\mathrm{n}]$ post interference cancellation in the digital domain using the cancellation mode as mentioned in the subscript, and (h)-(l) recovered and equalized $\mathrm{S}_{\mathrm{FR}}[\mathrm{n}]$ in the cancellation modes as mentioned in the subscript. These eye-diagrams are plotted for the link LAPAM4, and are for $10^{4}$ symbols of the signals.

for the received $S_{R I}[n]$ with and without analog domain suppression, respectively. Eye-diagrams of $\mathrm{S}_{\mathrm{RIC}}[\mathrm{n}]$ for the four cancellation modes DPT, DBG, ADPT, and ADBG are shown in Fig. 12(c-f), respectively. Eye-diagram of $S_{\mathrm{FR}}[\mathrm{n}]$ for mode ADPT/ADBG shows a better eye-opening than the modes DPT/DBG, even with a reduction in the number of available resolution bits. This improvement in the eye-quality is because of the SI-suppression performed using $\mathrm{S}_{\mathrm{TA}}(\mathrm{t})$, which allows the FE signal to re-claim the dynamic range of the oscilloscope's ADC. Fig. 12(g) and Fig. 12(l) show eye-diagrams for the received $S_{\text {RIC }}[n]$ with and without equalization in the mode UD, respectively.

Fig. 13 shows bath-tub curves for the equalized $S_{\mathrm{FR}}[\mathrm{n}]$. The 

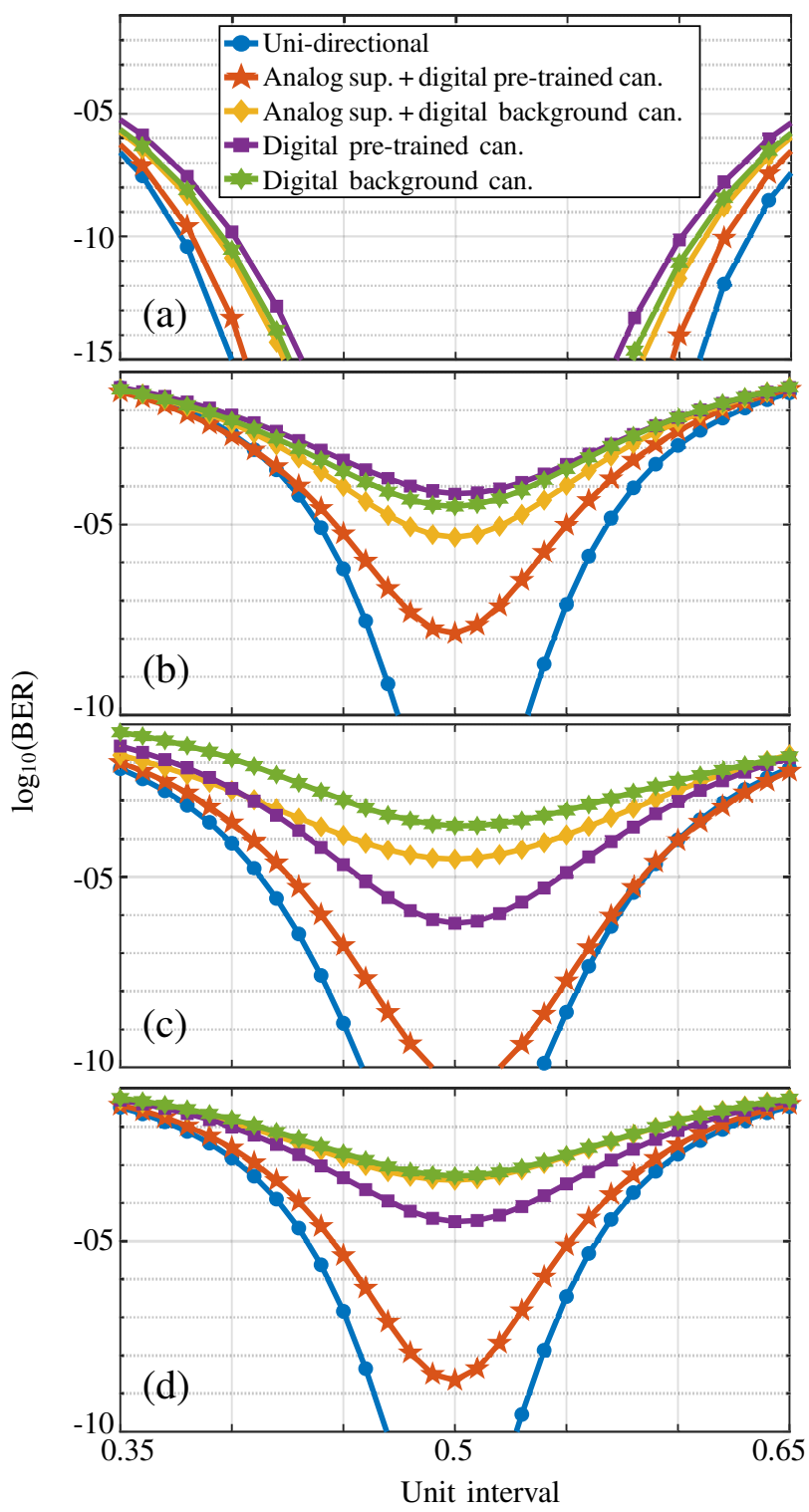

Fig. 13: Estimated bath-tub curves for the equalized FE signal $S_{\mathrm{FR}}[\mathrm{n}]$ of the demonstrated TFD links: (a) $\mathrm{LD}_{\mathrm{NRZ}}$, (b) $\mathrm{LA}_{\mathrm{PAM} 4}$, (c) $\mathrm{LC}_{\mathrm{PAM} 4}$, and (d) $\mathrm{LB}_{\mathrm{PAM} 4}$. For the links, the cross-correlation between the transmitted sequences $\mathrm{SQ}_{1}$ and $\mathrm{SQ}_{2}$ increases from (a) to (d). The links with the lower correlation show a better BER performance for the background cancellation modes.

curves have been plotted using the estimated BERs [46]. The relative BER performances of the demonstrated links for different cancellation modes can be summarized as follows:

Fig. 13(a): $\mathrm{LD}_{\mathrm{NRZ}} \rightarrow \mathrm{UD}<\mathrm{ADPT}<\mathrm{ADBG}<\mathrm{DBG}<\mathrm{DPT}$

Fig. 13(b): $\mathrm{LA}_{\mathrm{PAM} 4} \rightarrow \mathrm{UD}<\mathrm{ADPT}<\mathrm{ADBG}<\mathrm{DBG} \sim \mathrm{DPT}$

Fig. 13(c): LC $_{\mathrm{PAM} 4} \rightarrow \mathrm{UD}<$ ADPT $<$ DPT $<$ ADBG $<$ DBG

Fig. 13(d): $\mathrm{LB}_{\mathrm{PAM} 4} \rightarrow \mathrm{UD}<$ ADPT $<$ DPT $<$ ADBG $\sim$ DBG

The bath-tub curves show an improvement in the error performance with the SI-suppression for all the demonstrated TFD links. The $\mathrm{LD}_{\mathrm{NRZ}}$ shows a better error performance than the other links because of the used NRZ signalling scheme for the FE and NE signals. The BER curves, for the cancellation modes, ADPT and DPT, show a drop in the error performances with an increase in the operating baud rates for all links. On the other hand, for the modes ADBG and DBG, the BER curves for LAPAM4 (which supports the highest throughput) show improved error performances than both $\mathrm{LB}_{\mathrm{PAM} 4}$ and $\mathrm{LC}_{\mathrm{PAM} 4}$. This improvement in the error performance for $\mathrm{LA}_{\mathrm{PAM} 4}$ is because of the lower cross-correlation between the transmitted sequences $\mathrm{SQ}_{1}$ and $\mathrm{SQ}_{2}$. The link $\mathrm{LA}_{\mathrm{PAM}}$ has a low crosscorrelation as transmitting $\mathrm{SQ}_{1}$ and $\mathrm{SQ}_{2}$ at different baud rates, lowers their concurrent repetition frequency. This decreased cross-correlation facilitates a better interference cancellation in the background cancellation modes, which is consistent to the simulation results.

The demonstrated TFD link LA PAM4 $_{4}$, supports an aggregated bidirectional throughput of $101.2 \mathrm{Gbps}$ over a channel loss of nearly $10 \mathrm{~dB}$ at the Nyquist frequency. The bath-tub curves for link LA PAM $4_{4}$ show a raw BER better than $10^{-7}$ and $10^{-5}$ in the cancellation mode ADPT and ADBG, respectively, meeting the present-day error performance [48]. The demonstrated TFD link, thus supports a data transfer throughput of $100 \mathrm{Gbps}$ over a single-lane, even when the transceivers operate at different baud rates. This independence eliminates the need to have a dedicated clock synchronization procedure or a training sequence for cancellation of the NE interference in the transceivers.

All these measurements were performed using single-ended signals, bandwidth-limited BBPDs, and 12-inches co-axial patch cables, which have been used for connecting the BBPDs to the amplifiers $A_{1} / A_{2}$. The performance of the SECs used in DBG/ADBG can be further improved by using data sequences with low cross-correlation for the $\mathrm{FE}$ and $\mathrm{NE}$ data. The error performance of the demonstrated links can be enhanced significantly by using better components or in an integrated transceiver, where these limitations will not be present.

\section{CONCLUSION}

This paper introduces and validates the concept of true fullduplexing (TFD) for transceivers used in bidirectional links. The use of TFD in transceivers doubles the data throughput per lane and offers a reduction in routing density. The proposed TFD approach allows for the usage of independent modulation schemes and independent baud-rates by the transceivers on either side of the same electrical interconnect. This independence obviates the need of having a dedicated start-up protocol or a training sequence for the used transceivers. The proposed TFD transceivers use a correlation-based technique to support background cancellation of the near-end interference. We have successfully demonstrated a $100 \mathrm{Gbps}$ TFD link over a $1 \mathrm{~m}$ long coaxial cable with background interference cancellation, which is the highest bidirectional throughput reported to date for a single-lane interconnects.

\section{REFERENCES}

[1] J. Macri, "AMD's next generation GPU and high bandwidth memory architecture: FURY," in IEEE Hot Chips, 2015, pp. 1-26.

[2] D. S. Green, "Common Heterogeneous Integration and Intellectual Property (IP) Reuse Strategies (CHIPS)," [Online]. Available: https://www.darpa.mil/attachments/CHIPSoverview\% 20Sept212016ProposerDay.pdf [Accessed: 20-08-2020]. 
[3] A. Bechtolsheim et al., "OIF Workshop - $\mathrm{Cu}$ (see you) Beyond $112 \mathrm{Gbps}, "$ [Online]. Available: https://www.oiforum.com/ meetings-events/oif-webinar-cu-see-you-beyond-112-gbps/ [Accessed: 20-08-2020].

[4] F. O'Mahony et al., "The future of electrical I/O for microprocessors," in IEEE Symp. on VLSI Design, Automation and Test, 2009, pp. 31-34.

[5] D. Kehlet, "Accelerating Innovation Through a Standard Chiplet Interface: The Advanced Interface Bus," [Online]. Available: https://www.intel.com/content/dam/www/public/us/en/documents/ white-papers/accelerating-innovation-through-aib-whitepaper.pdf [Accessed: 20-08-2020].

[6] D. D. Sharma, "PCIe ${ }^{\circledR} 6.0$ Specification: The Interconnect for I/O Needs of the Future," [Online]. Available: https://www.brighttalk.com/webcast/ 17656/409679 [Accessed: 20-08-2020].

[7] R. Farjadrad, M. Kuemerle, and B. Vinnakota, "A Bunch-of-Wires (BoW) Interface for Interchiplet Communication," IEEE Micro, vol. 40, no. 1 , pp. 15-24, 2020.

[8] A. Shokrollahi et al., "A pin-efficient $20.83 \mathrm{~Gb} / \mathrm{s} /$ wire $0.94 \mathrm{pJ} /$ bit forwarded clock CNRZ-5-coded SerDes up to $12 \mathrm{~mm}$ for MCM packages in $28 \mathrm{~nm}$ CMOS," in IEEE ISSCC, 2016, pp. 182-183.

[9] D. Kehlet, "USB 3.2 Specification Language Usage Guidelines from USB-IF," [Online]. Available: https://www.usb.org/sites/default/ files/usb_3_2_language_product_and_packaging_guidelines_final.pdf [Accessed: 20-08-2020].

[10] M. Baxter, "SATA-IO Increases Interoperability Features with Revision 3.5 Specification," [Online]. Available: https://sata-io.org/sites/default/ files/documents/SATA\%20Spec\%20Rev\%203\%205\%20FINAL.pdf [Accessed: 20-08-2020].

[11] R. Smith, "Intel Announces Thunderbolt 3 - Thunderbolt Meets USB (At Last)," [Online]. Available: https://www.anandtech.com/show/9331/ intel-announces-thunderbolt-3 [Accessed: 20-08-2020].

[12] A. Roshan-Zamir, O. Elhadidy, H. Yang, and S. Palermo, "A Reconfigurable $16 / 32 \mathrm{~Gb} / \mathrm{s}$ Dual-Mode NRZ/PAM4 SerDes in $65 \mathrm{~nm}$ CMOS," IEEE J. Solid-State Circuits, vol. 52, no. 9, pp. 2430-2447, 2017.

[13] P. Upadhyaya et al., "A fully adaptive 19-to-56 Gb/s PAM-4 wireline transceiver with a configurable ADC in $16 \mathrm{~nm}$ FinFET," in IEEE ISSCC, 2018, pp. 108-110.

[14] M. Pisati et al., "6.3 A Sub-250 mW 1-to-56Gb/s Continuous-Range PAM-4 42.5 dB IL ADC/DAC-Based Transceiver in $7 \mathrm{~nm}$ FinFET," in IEEE ISSCC, 2019, pp. 116-118.

[15] E. Depaoli et al., "A $64 \mathrm{~Gb} / \mathrm{s}$ Low-Power Transceiver for Short-Reach PAM-4 Electrical Links in $28 \mathrm{~nm}$ FDSOI CMOS," IEEE J. Solid-State Circuits, vol. 54, no. 1, pp. 6-17, 2019.

[16] A. C. Durgun, Z. Qian, K. Aygun, R. Mahajan, T. T. Hoang, and S. Y Shumarayev, "Electrical Performance Limits of Fine Pitch Interconnects for Heterogeneous Integration," in IEEE ECTC, 2019, pp. 667-673.

[17] J. Fourniols, M. Roca, F. Caignet, and E. Sicard, "Characterization of crosstalk noise in submicron CMOS integrated circuits: an experimental view," IEEE Trans. Electromagn. Compat., vol. 40, no. 3, pp. 271-280, 1998.

[18] F. D. Mbairi, W. P. Siebert, and H. Hesselbom, "High-Frequency Transmission Lines Crosstalk Reduction Using Spacing Rules," IEEE Trans. Compon. Packag. Technol., vol. 31, no. 3, pp. 601-610, 2008.

[19] J. Chen, Y. Gu, and K. K. Parhi, "Low-Complexity Echo and NEXT Cancellers for High-Speed Ethernet Transceivers," IEEE Transactions on Circuits and Systems I: Regular Papers, vol. 55, no. 9, pp. 2827 2840, 2008.

[20] M. L. Honig, K. Steiglitz, and B. Gopinath, "Multichannel signal processing for data communications in the presence of crosstalk," IEEE Transactions on Communications, vol. 38, no. 4, pp. 551-558, 1990.

[21] M. L. Honig, P. Crespo, and K. Steiglitz, "Suppression of near- and farend crosstalk by linear pre- and post-filtering," IEEE Journal on Selected Areas in Communications, vol. 10, no. 3, pp. 614-629, 1992.

[22] G. D. Golden, J. E. Mazo, and J. Salz, "Transmitter design for data transmission in the presence of a data-like interferer," IEEE Transactions on Communications, vol. 43, no. 2/3/4, pp. 837-850, 1995.

[23] "IEEE 802.3 Ethernet Working Group," [Online]. Available: http://www. ieee802.org/3 [Accessed: 20-08-2020].

[24] G. Chandra and M. Malkin, "A full-duplex 10GBase-T transmitter hybrid with SFDR $>65 \mathrm{dBc}$ Over 1 to $400 \mathrm{MHz}$ in $40 \mathrm{~nm}$ CMOS," in IEEE ISSCC, 2011, pp. 144-146.

[25] P. Roo, S. Sutardja, S. Wei, F. Aram, and Y. Cheng, "A CMOS transceiver analog front-end for gigabit ethernet over CAT-5 cables," in IEEE ISSCC Dig. Tech. Papers., 2001, pp. 310-311.

[26] H. Tamura et al., " $5 \mathrm{~Gb} / \mathrm{s}$ bidirectional balanced-line link compliant with plesiochronous clocking," in IEEE ISSCC Dig. Tech. Papers, 2001, pp. 64-65.
[27] R. Mooney, C. Dike, and S. Borkar, "A $900 \mathrm{Mb} / \mathrm{s}$ bidirectional signaling scheme," IEEE J. Solid-State Circuits, vol. 30, no. 12, pp. 1538-1543, 1995.

[28] T. Takahashi, M. Uchida, T. Takahashi, R. Yoshino, M. Yamamoto, and N. Kitamura, "A CMOS gate array with $600 \mathrm{Mb} / \mathrm{s}$ simultaneous bidirectional I/O circuits," IEEE J. Solid-State Circuits, vol. 30, no. 12, pp. 1544-1546, 1995.

[29] T. Takahashi et al., " $110 \mathrm{~GB} / \mathrm{s}$ simultaneous bidirectional transceiver logic synchronized with a system clock," IEEE J. Solid-State Circuits, vol. 34, no. 11, pp. 1526-1533, 1999.

[30] H. Wilson and M. Haycock, "A six-port $30 \mathrm{~GB} / \mathrm{s}$ nonblocking router component using point-to-point simultaneous bidirectional signaling for high-bandwidth interconnects," IEEE J. Solid-State Circuits, vol. 36, no. 12, pp. 1954-1963, 2001.

[31] R. J. Drost and B. A. Wooley, "An $8 \mathrm{~Gb} / \mathrm{s} /$ pin simultaneously bidirectional transceiver in $0.35-/ \mathrm{spl} \mathrm{mu} / \mathrm{m}$ CMOS," IEEE J. Solid-State Circuits, vol. 39, no. 11, pp. 1894-1908, 2004.

[32] Jin-Hyun Kim et al., "A 4-Gb/s/pin low-power memory I/O interface using 4-level simultaneous bi-directional signaling," IEEE J. Solid-State Circuits, vol. 40, no. 1, pp. 89-101, 2005.

[33] N. Wary and P. Mandal, "Current-Mode Full-Duplex Transceiver for Lossy On-Chip Global Interconnects," IEEE J. Solid-State Circuits, vol. 52, no. 8, pp. 2026-2037, 2017.

[34] Y. Tomita, H. Tamura, M. Kibune, J. Ogawa, K. Gotoh, and T. Kuroda, "A $20 \mathrm{~Gb} / \mathrm{s}$ Simultaneous Bidirectional Transceiver Using a ResistorTransconductor Hybrid in 0.11- $\mu \mathrm{m}$ CMOS," IEEE J. Solid-State Circuits, vol. 42, no. 3, pp. 627-636, 2007.

[35] Y. Fan et al., "A $32 \mathrm{~Gb} / \mathrm{s}$ Simultaneous Bidirectional SourceSynchronous Transceiver With Adaptive Echo Cancellation Techniques," IEEE J. Solid-State Circuits, vol. 55, no. 2, pp. 439-451, 2020.

[36] M. T. L. Aung, E. Lim, T. Yoshikawa, and T. T. Kim, "A 3-Gb/s/ch Simultaneous Bidirectional Capacitive Coupling Transceiver for 3DICs," IEEE Transactions on Circuits and Systems II: Express Briefs, vol. 61, no. 9, pp. 706-710, 2014

[37] M. Jalalifar and G. Byun, "An Energy-Efficient Mobile Memory I/O Interface Using Simultaneous Bidirectional Multilevel Dual-Band Signaling," IEEE Transactions on Circuits and Systems II: Express Briefs, vol. 64, no. 8, pp. 897-901, 2017.

[38] S. Sen, F. Aryanfar, and C. Werner, "A Multiband Transceiver System in 45-nm CMOS for Extended Data Rate through Notchy Wireline Channels," IEEE Transactions on Circuits and Systems II: Express Briefs, vol. 58, no. 9, pp. 545-549, 2011.

[39] S. Goyal, P. Agarwal, and S. Gupta, "Demonstration of a Single-Lane 80 Gbps PAM-4 Full-Duplex Serial Link," in IEEE Hot Interconnects, 2019, pp. 32-35.

[40] S. Goyal, G. A. Parulekar, and S. Gupta, "A True Full-Duplex IO for High-Density High-Speed Interconnects," in IEEE ICECS, 2020, pp. 14.

[41] S. U. Rehman, M. M. Khafaji, C. Carta, and F. Ellinger, "A 10-Gb/s 20-ps Delay-Range Digitally Controlled Differential Delay Element in 45-nm SOI CMOS," IEEE Trans. Very Large Scale Integr. (VLSI) Syst., vol. 27, no. 5, pp. 1233-1237, 2019.

[42] T. Kim, S. Jang, S. Kim, S. Chu, J. Park, and D. Jeong, "A Four-Channel 32-Gb/s Transceiver With Current-Recycling Output Driver and On-Chip AC Coupling in 65-nm CMOS Process," IEEE Transactions on Circuits and Systems II: Express Briefs, vol. 61, no. 5, pp. 304-308, 2014.

[43] C. Yuan, A. Naguib, and S. Shekhar, "On the Design of Low-Power Hybrids for Full Duplex Simultaneous Bidirectional Signaling Links," IEEE Transactions on Circuits and Systems I: Regular Papers, vol. 67, no. 4, pp. 1413-1422, 2020.

[44] S. Mukherjee, A. Das, S. Seth, and S. Saxena, "An Energy-Efficient 3Gb/s PAM4 Full-Duplex Transmitter With 2-Tap Feed Forward Equalizer," IEEE Transactions on Circuits and Systems II: Express Briefs, vol. 67, no. 5, pp. 916-920, 2020.

[45] M. H. Hayes, Statistical Digital Signal Processing and Modeling, 1st ed. USA: Wiley Publishing, 1996.

[46] S. Haykin, Communication Systems, 5th ed. Wiley Publishing, 2009.

[47] I. Kollar and J. J. Blair, "Improved determination of the best fitting sine wave in ADC testing," IEEE T. Instrum. Meas., vol. 54, no. 5, pp. 1978-1983, 2005.

[48] Keysight Technologies, "Go to Market with 400G," [Online]. Available: https://www.keysight.com/in/en/assets/7018-07081/posters/ 5992-2143.pdf?success=true [Accessed: 30-09-2020]. 